Marquette University

e-Publications@Marquette

College of Education Faculty Research and

Publications

Education, College of

$10-1-2016$

\title{
Counselors' Social Class and Socioeconomic Status Understanding and Awareness
}

Jennifer M. Cook

Marquette University, jennifer.cook@marquette.edu

Gerard Lawson

Virginia Polytechnic Institute and State University

Accepted version. Journal of Counseling and Development, Vol. 94, No. 4 (October, 2016): 442-453.

DOI. (C) 1999-2019 John Wiley \& Sons, Inc. Used with permission. 


\title{
Marquette University
}

\section{e-Publications@Marquette}

\section{Education Faculty Research and Publications/College of Education}

This paper is NOT THE PUBLISHED VERSION; but the author's final, peer-reviewed manuscript. The published version may be accessed by following the link in the citation below.

Journal of Counseling and Development, Vol. 94, No. 4 (2016): 442-453. DOI. This article is (C) American Counseling Association and permission has been granted for this version to appear in e-

Publications@Marquette. American Counseling Association does not grant permission for this article to be further copied/distributed or hosted elsewhere without the express permission from American Counseling Association.

\section{Counselors' Social Class and Socioeconomic Status Understanding and Awareness}

\author{
Jennifer M. Cook
}

Department of Counselor Education and Counseling Psychology, Marquette University

Department of Leadership, Counseling, and Research, Virginia Tech

Gerard Lawson

Department of Leadership, Counseling, and Research, Virginia Tech

\begin{abstract}
Nine licensed professional counselors participated in semistructured interviews designed to reveal their awareness and understanding about social class and socioeconomic status (SES). Findings suggest that participants' descriptions of social class and SES often are incongruent with how they use the terms, and their awareness and understanding may be limited because of developmental factors, indicating potential clinical liabilities. The authors suggest that counselors should develop stronger social class consciousness to provide affirming counseling services and that further research on such strategies is needed.
\end{abstract}

\section{Keywords}

Social class, socioeconomic status, counseling 


\section{Introduction}

Social class indicators are ubiquitous in U.S. culture: Where people live, what they eat, how they speak, what clothes they wear (Payne, [ 39] ), and how people raise their children (Gillies, [ 18] ; Lareau, [ 31] ) can all point to social class values and worldviews. Popular culture, especially television, has defined what different social class groups are like. The television show The Beverly Hillbillies (Simon \& Ransohoff, [ 48] ) depicted what happens when people who are poor gain entry into the upper social class. The Fresh Prince of Bel-Air (Jones, [ 24] ) showed how people of color in the upper social class live. In 1988, Carsey and Werner normalized workingclass life with Roseanne. Later, with the advent of reality television, people in the United States became particularly privy to acute aspects of people's social class experiences, which most often represented dichotomies of class experiences (e.g., The Real Housewives of Orange County [Dunlop, [ 16] ], Welcome to Myrtle Manor [Poster \& Gips, [ 43] ]).

Whether or not people acknowledge it consciously, media images influence how people identify and understand social class groups and how people believe social class and socioeconomic status (SES) function. Often, these images are static, one-dimensional portrayals of social class groups that can instill stereotypes and bias. Although issues and images related to social class and SES are visible, in the United States, there is an overall reluctance to acknowledge that social class affects people's worldviews, values, and beliefs (Staton, Evans, \& Lucey, [ 52] ; West-Olatunji \& Gibson, [ 56] ). Accordingly, many people are hesitant or unwilling to talk about how social class affects people's lives because they are reluctant to recognize any class group as "valid" outside of the middle class. Because of this reluctance, counselors and clients alike may possess limited social class and SES understanding and awareness. This may affect counselors' ability to acknowledge and validate clients' social class and SES realities. The purpose of this article is to describe nine licensed professional counselors' (LPC's) awareness and understanding of social class and SES within the context of qualitative interviews. Accordingly, research findings and implications for counseling and future research are offered.

\section{Literature Review}

When discussing literature pertinent to social class and SES, first it is important to define relevant terms. Scholars have acknowledged that social class is difficult to define (Aronowitz, [ 4] ; Liu, Soleck, Hopps, Dunston, \& Pickett, [ 35] ), and therefore it is challenging to conduct research and develop guidelines for counseling practices that are conscious of social class. Indeed, definitions of social class range from equivocation with SES to a more complex construct that includes a multidimensional expression of culture, including values, family meanings, attitudes, beliefs, practices, and language (Liu, Soleck, et al., [ 34] ). The latter description is emerging as a more comprehensive approach to understanding social class as a cultural construct. Because of the construct's complexity, researchers continue to investigate, explore, clarify, and explain social class and its implications for counseling.

Socioeconomic status is an objective, ranked system that designates individuals' economic value based on their income, education, and occupation (Brown, Fukunaga, Umemoto, \& Wicker, [ 7 ] ; Muntaner, Eaton, \& Diala, [ 37] ). SES is quantified easily, and it has the capacity to shift rapidly if individuals' income, education, or occupation changes. Social class is a more subjective, yet often ranked, term that integrates individuals' SES factors with the totality of attitudes, beliefs, consciousness, values, behaviors, and interactions that affect their personal and group worldviews based on their social location, resources, and experiences with their social class affiliations (Kraus, Piff, Mendoza-Denton, Rheinschmidt, \& Keltner, [ 28] ; Liu, Ali, et al., [ 34] ; Ostrove \& Cole, [ 38] ; Smith, [ 50] ; Smith, Li, Dykema, Hamlet, \& Shellman, [ 51] ). Social class designations and identities are influenced often by social stratification, class mobility prospects, and classism. Furthermore, social class experiences are difficult to quantify. If SES variables change, individuals may identify as part of a different social class group. 
In many cases, social class is reduced solely to discussions of SES because SES is discrete and measureable (Brown et al., [ 7] ; Liu, Ali, et al., [ 34] ). Income, education, and occupation are a snapshot of economic standing at a particular moment. Although these factors say something about what people have obtained, they do little to describe how they actually live or experience the world based on their economic status. This lived experience is the main reason why SES cannot be used interchangeably with the term social class. In the counseling literature, some authors use the term social class, others use the term SES, and others use both terms synonymously. Significant complications can arise when scholars use the terms social class and SES imprecisely or interchangeably (Kurtz, [ 30] ; Liu, Ali, et al., [ 34] ). For example, researchers sometimes claim to measure participants' social class, yet they use SES factors to do so (Kraus, Côté, \& Keltner, [ 27] ; Ranchor, Bouma, \& Sanderman, [ 44] ). Furthermore, via a content analysis of three counseling journals between 1981 and 2000, researchers (Liu, Ali, et al., [ 34] ) found 480 different terms that were synonymous with social class. The paucity of clear social class definitions is a common issue when exploring social class literature, and such issues are reflected in the findings of this study.

Nonetheless, SES is a necessary component of social class. For example, people's finances often determine their access to resources, such as educational opportunities, nutritional foods, and housing, and, in turn, these resources contribute significantly to people's power and their privilege (Beeghley, [ $\underline{5}$ ] ; Brown et al., [ 7] ). Therefore, the more economic resources people have, the more opportunities or life chances they have. Conversely, the fewer economic resources people have, the more limited their opportunities and life chances are. This statement is true particularly in capitalistic countries like the United States. Capitalism is an economic structure, and it is also a social structure, both dependent on and undergirded by social stratification. Social stratification refers to a society's hierarchical, layered structure and how a society's valued resources are distributed within that structure (Beeghley, [ 5] ). Valued resources include SES factors of income, education, and occupation, as well as the aforementioned concepts of power and privilege. Embedded in social stratification is the concept of class mobility. Class mobility refers most often to upward class mobility: One's ability to move from a lower social class group to a higher social class group (Staton et al., [ 52] ). However, class mobility is both upward and downward, and many more U.S. citizens experience downward rather than upward mobility (Bradbury \& Katz, [ 6 ] ; Sawhill \& Morton, [ [46] ).

\section{Impact of Social Class}

As early as 1974, researchers began to address social class and counseling (Lorion, [ 36] ; Pettit, Pettit, \& Welkowitz, [ 41] ; Sladen, [ 49] ; Sue \& Sue, [ $\underline{53}$ ] ); however, these ideas were not incorporated significantly for almost three decades. Since 2000, researchers have begun to revisit social class (Liu, [ 32] ) and discuss the impact social class has on people's experiences. For example, researchers found that social class experiences can affect personality variables (Ranchor et al., [ 44] ), and that social class status can affect how individuals perceive themselves and their capabilities, especially when they compare themselves to people in other social class groups (Kudrna, Furnham, \& Swami, [ 29] ). Furthermore, in a three-study quantitative project ( $\mathrm{N}=387)$, Kraus et al. ([ 27] ) discovered that people from a low social class judge emotions more accurately than people from a high social class. The results of these studies suggest that social class group experiences may have more farreaching effects than simply access to resources: They suggest that people in different social class groups view and interact in the world differently.

Hoadley and Ensor ([ 21] ) discovered that teachers in a working-class context prioritized students' personal development, as opposed to teachers in a middle-class context, who prized knowledge acquisition, subject knowledge, and overall student cognitive development. These findings are consistent with Lareau's ([ $\underline{31}]$ ) longterm study with 12 working-class and middle-class families. She found that Black children raised in working-class homes were more similar to White children raised in working-class homes than to Black children raised in middle-class homes. The same comparisons were true for White children. Lareau posited that the similarities were not due to race but rather to social class norms, and the differences between class groups were most salient with regard to parental child rearing conceptualizations and the way the parent-child relationship 
functioned. Both studies revealed that the differences between social class values, initiated by the family system, made an indelible impact on how children and adults viewed themselves, the world, and their interactions.

Counseling scholars and researchers have called counselors to acknowledge how social class affects the counseling relationship. For example, Vontress ([ $\underline{54}]$ ) pointed out that although clients run the gamut of social differences, counselors tend to be middle class, and, subsequently, hold middle-class values and worldviews. Furthermore, he stated that the counseling setting, counselors' traditional displays of empathy, the structure of counseling, mandatory client self-disclosure, counselors' lack of personalism, and counselors' communication style often reflect middle-class values and worldviews and can hinder the counseling process for clients from lower social class groups. In addition, Kim and Cardemil ([ 25] ) shared their clinical experience with clients from a low social class and indicated that counselors must "attend to social class issues in an explicit and ongoing manner" (p. 29) with regard to social class assessment, the integration of social class into the counseling process, and attention to class differences between counselors and clients.

\section{Social Class Theoretical Frameworks}

The Social Class Worldview Model (SCWM; Liu, [ 32] ), the Social Class Worldview Model-Revised (SCWM-R; Liu, [33] ), and the Social Class and Classism Consciousness Model (SCCCM; Liu, [ 33] ) are theoretical frameworks that provide a context for how counselors can understand social class. Liu ([ 32] , [ 33] ) created the SCWM and the SCWM-R so counselors could better understand how people interpret and make meaning of their thoughts, feelings, activities, economic settings, and culture related to their social class understanding, worldviews, and experiences. Furthermore, these models suggest that people from different social class groups have different values, worldviews, points of reference, and strengths.

To fully understand the implications of the SCWM (Liu, [ 32] ) and the SCWM-R (Liu, [ 33] ), individuals must develop social class consciousness. The SCCCM (Liu, [ 33] ) is a social class developmental model, similar to the Ethnic Identity Development Model (Phinney, [ 42] ) and the White Racial Identity Model (Helms, [ 20] ). The SCCCM reveals stages of social class awareness and consciousness via levels and statuses. The SCCCM has three levels: (a) no social class consciousness, (b) social class self-consciousness, and (c) social class consciousness. Within each level, there are several statuses. With each status, individuals examine their social class perceptions of self, peers, others, and society, and, typically, ideological and practical shifts occur. When people experience the first level, no social class consciousness, they progress through the statuses of unawareness, status position saliency, and questioning. In the second level, social class self-consciousness, people experience exploration and justification, despair, the belief that the world is just, and intellectualized anger and frustration. In the third level, social class consciousness, people experience reinvestment, engagement, and equilibration.

On the whole, the SCCCM is a linear model, and one must, for example, move through the unawareness status before proceeding to the questioning status (Liu, [ 33] ). However, people can and do fluctuate between levels and statuses and revisit levels/phases at different developmental junctures. Liu ([ 33] ) posited that people who have progressed through multiple SCCCM levels and developed a keen sense of their social class identity recognize their ability to use and benefit from different statuses when contexts and situations change. Liu did not elaborate on what situations or contexts may call for one to function in earlier social class development levels/phases. The SCCCM is the main framework through which the findings of this study are understood.

\section{Purpose of the Study}

Although scholars (Hoadley \& Ensor, [ 21] ; Lareau, [ 31] ; Liu, Soleck, et al., [ 34] ) have identified significant information about social class and how social class affects individuals, they have not researched what comprises counselors' social class understanding or awareness (e.g., values, beliefs, awareness, worldviews about social class) or how developed counselors' understanding and awareness may be, nor have they posited how these 
aspects may affect the counseling relationship. The purpose of this study was to describe the social class awareness and understanding of LPCs via phenomenological, qualitative methods.

\section{Method}

Currently, scant empirical studies address counselors' awareness and understanding of social class and SES. Therefore, we chose a qualitative, phenomenological design for this exploratory study. In phenomenological studies, researchers acknowledge the constructivist nature of reality and the phenomenon under investigation and seek to explain how participants understand that phenomenon (Hays \& Wood, [ 19] ). Thus, the first author conducted face-to-face semistructured interviews with nine LPCs in one state in the southeastern United States.

As is the case with many qualitative studies, the results from this study yielded a large body of significant data that included five salient categories that are applicable and beneficial to different counseling professionals (e.g., counseling practitioners, counselor educators, counseling supervisors), with each category representing foci different enough to warrant more than one article (American Psychological Association, [ 2] ; Knapp, [ 26] ; Hunt, [23] ). Therefore, it was deemed appropriate to present study data in multiple articles to report findings within the context and frameworks indicative of the categories that arose from the data, and to do so with the richness, texture, and thoroughness expected with phenomenological studies.

\section{Participants}

The first author used purposeful, criterion-sampling techniques to identify participants who met the following inclusion criteria: (a) were current practicing counselors in a clinical mental health or private practice setting in the designated state (b) were LPCs in the designated state; and (c) completed graduate counselor training program no more than 10 years before participation. Participants were excluded if they earned their master's degree in counseling from either of the two universities with which we had a relationship. We recruited LPCs because of the rigor and clinical experience required to become licensed, and we further narrowed the study focus by selecting LPCs with the specific professional identity of working in clinical mental health or private practice settings. We made this choice to understand findings within these professional practice scopes.

Completed graduate counselor training was limited to no more than 10 years, so participants were likely to have received multicultural training during their master's program.

The first author recruited participants using the state LPC database, the state counseling association member database, and various public Internet information sources (e.g., private practice websites, "find a therapist" websites). Initially, the first author contacted participants via e-mail or phone and asked screening questions to insure they met recruitment criteria. Participants were not screened for or excluded based on demographic factors such as race, gender, or age.

In phenomenological studies, the number of participants is not predetermined, and the first author recruited and interviewed participants until the data were saturated (Creswell, [ 15]; Rossman \& Rallis, [ 45] ).

Participants were accepted into the study on a first-come, first-served basis if they met the inclusion criteria. Eleven participants qualified for the study, but two were not interviewed because data had reached saturation, so nine counselors participated in this study. All participants identified as female. Three participants identified as African American/Black, and six identified as White. Participants' ages ranged from 32 to 59 years, with a mean age of 42.4 years. At the time of the study, all participants identified on the middle social class spectrum based on self-report. Participants completed their counseling master's programs between 2004 and 2009, and eight graduated from programs accredited by the Council for Accreditation of Counseling and Related Educational Programs. All participants were LPCs who held no other counseling licenses and had between 5 and 11 years of clinical experience ( $M=8.1$ years). Seven participants worked in clinical mental health settings and two in private practice. Geographically, three participants worked in rural environments, two in urban environments, two in suburban environments, one in a town, and one in both rural and urban environments. 


\section{Data Collection Procedure}

University institutional review board (IRB) approval was granted before any participant recruitment, and all research procedures were conducted in accordance with IRB protocols and the ACA Code of Ethics (American Counseling Association, [ 1 ] ). Participants provided written consent before being interviewed, and they received a copy of the consent forms for their records. During the consent process, participants chose a pseudonym, if they so desired. If not, the first author assigned a pseudonym. Interviews were audio recorded for transcription purposes and video recorded for researcher review. After the interviews were transcribed, transcripts were compared with the recorded material.

Participants engaged in one semistructured interview during a 1-month period in 2013. One interview session was deemed appropriate; there is no convincing evidence that multiple interviews are superior to single interview sessions (Seidman, [ 47] ). The most rigorous interviews follow a rational process and are replicable and well documented (Seidman, [ 47] ), and, presumably, participants' current social class awareness and knowledge would not have changed significantly in a short period of time if an additional interview was added. If additional information came forth, participants added that information during member checking. We constructed open-ended interview questions devised to unearth participants' awareness and understanding about social class and SES (Christensen \& Brumfield, [ 10] ; Seidman, [ 47] ). Examples of these open-ended interview questions are "What comes to mind when you hear the term social class?" and "What comes to mind when you hear the term socioeconomic status?" Although explanatory probes to assist participant' responses were approved in the IRB protocol, after the pilot interviews, we decided not to use them so participants could share their established awareness and understanding rather than integrating new knowledge during the interview process. The first author collected participant demographics during the interview process, and participants did not give written responses of any kind.

\section{Role of the Researcher}

We recognize there are no value-free research pursuits, and we acknowledge our social location, power, privilege, and values, and the iterative process inherent to reducing bias in our research. The first author identifies as a White woman, raised in an upper-lower social class environment (Warner, Meeker, \& Eells, [ 55] ), which means that although her family was working class, she did not have full access to middle-class resources and values. In her adult life, she gained entry into the middle social class via higher education. Because of her professional identities as counselor, supervisor, counselor educator, and multicultural advocate, she acknowledges her emic perspective because she has conducted interviews with people with whom she shares a professional identity. She also recognizes that she may be more familiar with social class because of her professional and personal awareness, knowledge, skills, and experiences, which may be different from the participants that she interviewed. She lives solidly in a postmodern context and operates from a social constructionist perspective. She used this viewpoint to help mitigate possible biases in the interview process and data analysis, because she sought to understand the multiple personal truths participants had constructed about social class (Anderson, [ 3 ] ; Gergen, [ 17] ).

\section{Trustworthiness}

Techniques used to ensure research trustworthiness included member checking; consistent, thorough documentation; crystallization; triangulation; and peer debriefing. We invited participants to member check (Rossman \& Rallis, [ 45] ) their transcripts and allowed them to amend and add to their transcripts to aid clarity and accuracy. We e-mailed transcripts to participants within 1 week of their interviews and gave them 2 weeks to check their interview transcripts. Six out of nine participants chose to member check their transcripts. We kept a detailed audit trail and recorded field notes after the first author completed each interview to record contextual variables, insights, and reflections. The field notes provided a thick description of events and data and aided us in data analysis (Rossman \& Rallis, [ 45] ). In addition to field note review, we examined interview 
video recordings multiple times during analysis, which aided in crystallization. Triangulation was obtained via multiple data points in conjunction with knowledge contained in the SCCCM (Liu, [ 33] ).

We recruited two peer debriefers with qualitative research experience to review transcripts and ensure coding accuracy, to discuss emerging themes and research findings, and to process any potential bias in interview proceedings or data analysis. Each of the two peer debriefers used open coding to review two different transcripts. Both peer debriefers coded the first interview transcript, one peer debriefer coded the third transcript, and the other coded the sixth transcript. This approach involved having peer debriefers go line by line through the transcripts, developing their own codes as the codes emerged for them from the data. The purpose of this approach was for the debriefers to act independently in the coding procedure so their coding results could be compared with our coded transcripts for consistency and accuracy. After we completed axial and selective coding described earlier, the peer debriefers reviewed the categories, themes, and the codes within categories and themes to ensure accuracy. Also, peer debriefers helped process potential bias, such as frustration with some participant responses, to ensure trustworthiness, consistency, and applicability. In summary, the peer debriefing process was a system of checks and balances used to increase researcher objectivity in a subjective methodology.

\section{Data Analysis}

Qualitative data analysis is an interpretive enterprise that involves several steps to uncover categories, themes, and meanings (Christensen \& Brumfield, [ 10] ; Rossman \& Rallis, [ 45] ). The first author began initial coding after two interviews were completed. This procedure aided her in knowing quickly when the data reached saturation via constant comparison (Holton, [ 22] ). Furthermore, throughout the coding processes, she kept detailed notes of hypotheses, assumptions, biases, and reflections that developed while she was immersed in the data (Rossman \& Rallis, [ 나] ).

As a single coder with peer reviewers, the first author coded the research data in several stages, following Corbin and Strauss's ([ 12] , [ 13] ) model of open, axial, and selective coding. During coding, she broke down the units of data analytically, line by line (Corbin \& Strauss, [ 12] ; Holton, [ 22] ). She considered each interview a unit of data. During open coding, initial concepts emerged, and she noted them by underlining words and phrases, making color notations, and labeling them with in vivo codes. At the end of open coding, there were 1,330 codes. During axial coding, the first author formed categories based on the in vivo codes identified during open coding. She retained in vivo codes and placed them within overarching categories. This process yielded 26 categories that included designations such as the impact of education, beliefs about the American Dream, and misconceptions about social class. In the final stage, selective coding, five salient selective categories surfaced that explained "central processes of the phenomenon of study" (Buckley, [ 8] , p. 124) within the context of their relationship to the research questions. Data were triangulated and compared with the literature, particularly the aforementioned SCCCM framework. In the following paragraphs, we report the findings embedded in one selective category that includes two axial categories and corresponding themes: (a) participant descriptions of SES and social class and (b) participant use of the terms social class and SES.

\section{Findings}

In this section, we focus first on the category of participant descriptions of SES and social class. The themes emerged based on consensus descriptions formed from triangulated data (see Figure [NaN]). Then, we describe the second category of participant use of the terms social class and SES. The two themes associated with this category are indicative of how participants operationalized the terms SES and social class during the interview process, and the themes illustrate how they often moved away from their initial complex descriptions of the terms. Participant quotes illustrate each theme. 


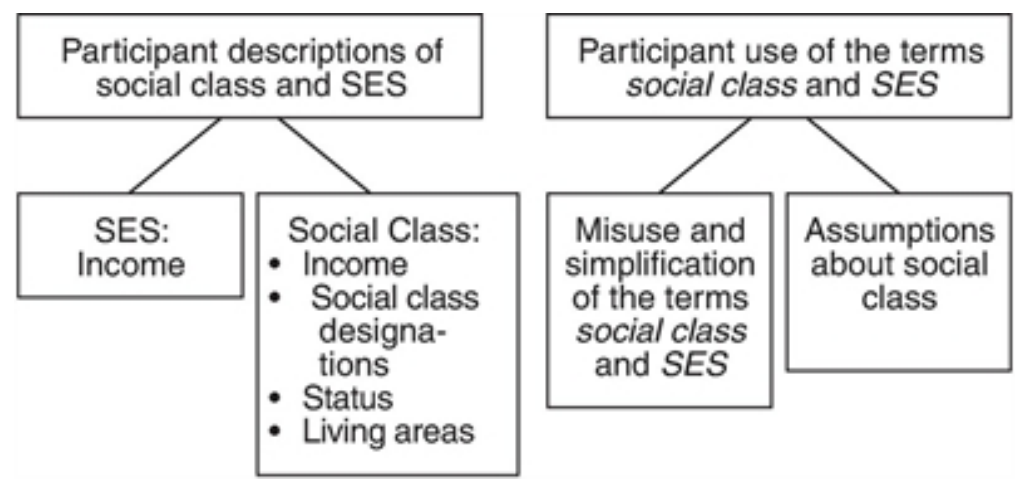

Figure 1: Categories and Themes Model

Note. SES = socioeconomic status

\section{Category 1: Participant Descriptions of SES and Social Class}

When asked directly how they understood social class and SES, participant responses varied greatly, both in terms of the number and types of aspects they believed comprise social class. Although the majority of participants cited multiple aspects for both social class and SES, two different participants stated a singular aspect for both SES and social class, and, in both cases, that aspect was money/income. Participants listed between one and six aspects to describe social class and between one and five aspects to explain SES. One theme emerged for SES, and four themes emerged for social class.

SES and social class: Income. Income or money was a shared theme for both SES and social class. Seven participants used this theme to describe social class, and eight participants used it to describe SES. Income was the only theme related to SES: There were two instances in which two participants agreed about what comprised SES outside of money/income, and with nine participants, a consensus of two cannot be triangulated. These themes are reported together because all participants except one intertwined income with other diverse factors when they explained SES. This singular participant, Joan, stated, "Mostly, how much money you are making."

Sophie stated, "Income. How much you make," when asked to describe SES. When probed, she added, "Maybe just below poverty line or poverty." Linda, too, noted income in addition to how people might categorize themselves:

Income, basically and a sense of where one's place is, I suppose, as well. Some people call themselves middle class who by straight percentages would clearly be more in the upper to upper-middle class. Even people who we'd consider to be under or within $2 \%$ or $3 \%$ of the poverty line would probably still call themselves middle class, even though by sense of scale and looking at a bell curve, they would still be considered poor or underserved.

When Averie described SES, she discussed income, yet she integrated additional aspects to describe how money might function. She stated,

I look ... more so at how financially stable the household was or is, rather. I look at whether or not you have someone who's living paycheck to paycheck. Someone who's able to comfortably pay all of their bills, and then maybe, put some away. Someone who's able to pay all of their bills and put a lot away and still have plenty. I look at it that way.

Similarly, when asked what comes to mind when she hears the term social class, Averie mentioned income and acknowledged additional facets: 
I think about pockets or groups of people who are connected by status, whether it's working class, middle class, upper class. ... I think about the type of education someone may have had. I think about the type of environment they grew up in, in terms of were they raised in a suburban area, rural, or urban? I think about whether or not they grew up in a two-parent household or single parent. Whether or not they live with just their immediate family, or was there extended family that lived there as well?

Joan acknowledged a similar complexity: "For social class, I think about ethnicity, region where you're living, how much money you make, what kind of groups you're a part of, all that sort of thing." Linda stated,

A combination of both economic status and also one's sense of roots. In the United States, of course, class appears to be more fluid than it is ... I sort of connect it more to economics than anything.

For her definition of SES, Jane mentioned income and then parsed the concept further: "We can break it [SES] down. We could precise the terminology [sic] and think, what's your background, your education? How does that contribute to your income?" Madison also named other factors: "Money. Location. And I have to say maybe even generational." Paula stated, "Education and money. Education and income," whereas Ruby Rose offered, "Money. And then employment." All of these quotes illustrate how the majority of participants discussed income as a component of SES and social class, and they did so in a nuanced way that incorporated multiple factors.

Social class: Social class designations. Five participants discussed social class designations associated with different social class groups (e.g., low social class, middle social class) when they defined social class. Paula noted, "The stratification of middle, upper, lower." Another participant, Christine, talked about social class designations and tied those designations to income: "Generally with social class what comes to mind is poverty, rich, middle class. I'm looking at the financial levels." Linda, a participant who also discussed class designations in terms of class stratification, stated, "I sort of connect it more to economics than anything." Both Christine and Linda connected social class designations with income, whereas Paula was not as clear about the connection to income. For these three participants, social class group designations were a salient feature of defining social class.

Social class: Status. Three participants discussed status. Averie appeared to use the term status in a more general sense when she stated, "I think about pockets or groups of people who are connected by status, whether it's working class, middle class, upper class." Madison and Jane mentioned status as well and how they understood status as more linked to prestige or power. Madison shared tentatively, "Money. Yeah, I guess prestige, status. I guess those are the main things." Jane discussed status in terms of how power is distributed across the social class spectrum:

The haves and have-nots basically ... I think that there can be such a presumptuousness with those who have. The comfort level of blindness of the empowered versus the "having to note everything" of the disempowered. And I mean that as far as social status and income, both.

All three quotes illustrate participants' recognition of the role status plays in their definitions of social class. Although Averie described status a bit differently than did Jane and Madison, it was still a salient concept for all three women.

Social class: Living areas. Three participants talked about the places where people live as related to social class. For example, Joan discussed the complexities: 
It seems like that's how people are defining social class: where you live, what neighborhood are you a part of, all of those kind of things.... What school do you go to? ... Which blurs the lines a little bit, because sometimes people are living in a more impoverished area, but they're part of a higher social class. It just depends the region in which people might live as well as the neighborhood of which people may be a part.

Averie noted, "I think about the type of environment they grew up in, in terms of, were they raised in a suburban area, rural, urban?" Sophie shared how she noticed a regional difference in the types of dwellings based on social class groups. She said in her current locale people who are poor live in trailers. She added, "Where I grew up, there would be trailer parks, but it was more ... it was like retirement, it was more for elderly [people]."

Like with the consensus description status, each participant who spoke about where people live as an aspect of social class did so a bit differently from one another. Nevertheless, three participants viewed status as an integral component of social class.

\section{Category 2: Participant Use of the Terms Social Class and SES}

Participants were asked directly how they understood social class and SES only one time, at the beginning of the interview process, and the rest of the interview focused on matters related to social class and SES (e.g., family of origin, clinical practice). When participants used the terms SES and social class, they often did so in ways that were not congruent with how they explained SES and social class initially. Two themes emerged related to how participants discussed social class and SES when not asked directly how they conceptualize these terms: (a) misuse and simplification of the terms social class and SES and (b) assumptions about social class and SES.

Misuse and simplification of the terms social class and SES. Four participants misused and simplified social class and/or SES during the interview process either by using the terms interchangeably or by combining the two terms into one term. For example, as Averie discussed social class, she changed to the term SES:

When I look at middle class, I see parents who are maybe able to just have one job and are able to actually support their kids in that area. Where[as] someone with a lower socioeconomic [status], they may be working two jobs.

Similarly, as Sophie discussed income, she equated people's income deficiencies with knowing to which social class group they belong:

Maybe just based on income or something, or if they received food stamps or SNAP benefits, or all the different benefits they have out there.... Or, just if they can't pay their bills or [are] struggling, they kind of have an idea of what class they're in.

Correspondingly, sometimes participants combined social class and SES into one term. Ruby Rose combined the terms when she stated:

I think people who would consider themselves poor are just ... they are not thinking about how poor they are, they are just trying to get by. They are not thinking of their socioeconomic class where people who are striving for "I want to rule the world," you know, "I want to run a corporation," "I want to have the Bentley in the driveway," they are striving for this top echelon in the socioeconomic class and they know it and they are striving for it.

Likewise, Linda combined these terms when she shared, "The other piece, of feeling stupid ... wherever you are, is if you're in a situation where you're feeling a power differential and there is a power differential between SES classes." 
These quotes illustrate the ways that participants misused, confused, or conflated SES and social class. By doing so, participants moved away from their initial, more complex explanations of social class.

Assumptions about social class. Four participants shared thoughts or experiences related to social class in which they revealed inexperience with the complexities of social class. For example, Sophie stated,

Some of these kids are from the lower class. They may not have clean clothes or don't always have food, but yet they'll come in and have a phone. They'll come in with an iPhone or they'll come in and say, "We just got the newest PS3 or PlayStation 3." So sometimes I wonder about priorities. Because if you can afford a PlayStation, then why can't you feed them or give them decent clothes?

Joan, too, shared her view:

People who live in a more impoverished area, there may be someone who is in a higher social class because they get to go to college and they get to be part of a group of people-because of scholarships or because of financial aid - that they might not have had an opportunity to be with otherwise.

Paula discussed how she viewed obtaining her post-high school education:

I took it for granted. Yeah. It's just the way it was going to be. I knew growing up that this was the way, this is what you will do and I never questioned that they [her parents] would pay for it. It was just, I had an older brother and an older sister so I saw what they did and ... it was that era too. It wasn't ... it was like culture expected that, our teachers expected that of us, the neighbors expected it of us. It was the path that everybody seemed to be doing.

These quotes illustrate assumptions about social class. Sophie's description revealed a lack of understanding and awareness about how people in a low social class might hold different values about how to use money than do people in other social class groups. Joan's commentary seemed to point to the belief that people from a low social class change social class groups automatically if they go to college. Finally, Paula stated she took going to college "for granted," yet she seemed to hold the belief that everyone went to college and that it was "expected" by culture.

\section{Discussion}

Social class is a complex concept that includes people's attitudes, beliefs, consciousness, values, behaviors, and interactions that affect their personal and group worldviews based on their social location, resources, and experiences with their social class affiliations (Kraus et al., [ 28] ; Liu, Soleck, et al., [ 34] ; Ostrove \& Cole, [ 38] ; Smith, [ 50] ; Smith et al., [ 51] ). SES is composed of the discrete factors of income, education, and occupation (Brown et al., [ 7] ; Muntaner et al., [ 37] ), and is a key component of social class. When participants were asked initially to describe what comes to mind when they hear the term SES, eight participants discussed between two and five factors, whereas only one participant gave a singular response. Notably, none of the participants named all three SES factors. Eight participants indicated money/income, whereas only two participants cited education. One participant referenced the prestige associated with employment at particular companies, yet this description of employment did not match the rankings associated with particular occupations, which is a crucial definitional component of SES.

When asked directly to describe social class, most participants revealed multifaceted understanding and awareness, indicating between two and six factors. Only one participant gave a singular response, and, congruent with SES, the participant named money as the sole factor. Although most participants listed more than one factor related to social class, few went beyond simply listing different aspects, and they were seemingly unable or reluctant to further explore the aspects they named. It is not surprising, then, when 
participants discussed social class outside of defining it (i.e., when they used the term operationally), most did so in a way that was not always congruent with how they defined social class initially. For example, participants used the terms interchangeably or conflated the terms-probably unintentionally. Furthermore, they strayed from the multiple dimensions they spoke about initially and spoke more frequently about social class unilaterally in terms of finances. However, participants were more consistent with their use of the term SES. When participants were asked directly to describe SES, the theme that emerged was income, and throughout the interview process, participants relied consistently on income or money as the salient feature of SES, and they rarely mentioned other factors.

Participants' terminology usage was similar to the terminology issues found in counseling literature related to social class (Liu, Ali, et al., [ 34] ). The lack of congruency found in the data may be explained in part by social desirability: Participants may have had a cultural sense of appropriate answers to provide when they were asked directly to describe a particular phenomenon (in this case, social class and SES). However, this issue may be explained further through the lens of the SCCCM (Liu, [ 33] ). The SCCCM provides a developmental perspective of how people's social class consciousness develops. The early stage of social class consciousness development, no social class consciousness, is marked by limited understanding about social class and how it functions. Liu ([ 33] ) posited that people in this stage are aware that social class groups exist and that they are a part of a social class group, yet there is (a) no real sense about how social class functions, (b) a lack of awareness about one's social class privilege, and (c) a deficient understanding about how class inequality began or is perpetuated. It is reasonable to conclude that the majority of participants in this study fell in this developmental category. This issue is seen most clearly in the findings when participants misused, conflated, or simplified social class and SES and when they conveyed a sense of naiveté about how social class groups function. Through the lens of the SCCCM, this unawareness is an expected part of the developmental process. Therefore, it is understandable that participant responses suggest that some participants had an inkling that social class involves more than income and money, yet at the same time, most struggled to articulate the multifaceted dimensions of social class when they used the term outside of defining it.

Participants' awareness and understanding of social class were confined primarily to the economic realm or to aspects that contained some association with income. For example, high, middle, or low social class designations are, in part, determined by finances, as are status and living areas, the themes associated with the category of participant descriptions of SES and social class. Income and monetary resources are an important part of social class, yet what is missing from participants' responses is how income affects people's worldviews, values, beliefs, ways of being, and attitudes (Kraus et al., [ 28] ; Liu, Soleck, et al., [ 34] ; Ostrove \& Cole, [ 38] ; Smith, [ 50] ; Smith et al., [ 51] ). These missing links are crucial for understanding how social class plays a cultural role in people's lives, particularly the lives of clients with whom counselors work.

Participant quotes in the theme assumptions about social class illustrated how some participants may not understand how social class group membership can influence people's ways of being and understanding, including how money is allocated, what resources are available and accessed, and communal value structures. Researchers have shown that values differ by social class group and are initiated by and embedded in the family system (Hoadley \& Ensor, [ 21] ; Lareau, [ 31] ). Because most counselors are middle class (Vontress, [ 54] ), clients' social class values may differ significantly from counselors' social class values, and misunderstanding clients' cultural worldviews because they differ from those of the counselor can affect the counseling relationship negatively. The majority of participants $(n=7)$ worked in clinical mental health settings, many of whom served clients from social class groups different from their own. Kim and Cardemil ([ 25] ) suggested that counselors attend to clients' social class experiences continually and explicitly, yet the data in this theme indicate social class assumptions that may interfere with doing so. 


\section{Limitations}

There are limitations associated with this study. First, the sample represented nine LPCs who worked in clinical mental health or private practice settings in one southeastern state; thus, there may be different understandings of social class and SES in other regions, and it is appropriate to investigate the views of counseling professionals who work in other settings. Second, the criterion-based sample was not designed to exclude participants from a variety of demographic groups, and the views of men and racial/ethnic groups other than African American/Black and White were not included in this study. The 1:2 ratio of African American/Black to White participants in this study may have affected study outcomes. Third, the use of semistructured interviews with a single interviewer made data collection and analysis vulnerable to bias despite the fact that the first author took measures to insure trustworthiness, to execute interviews consistently, to build rapport with participants, and to empower participants throughout the interview experience (Seidman, [ $\underline{47}]$ ).

\section{Implications and Future Research}

While we acknowledge participants' social class understanding as developmentally appropriate given their current social class awareness and knowledge (Liu, [ 33] ), concurrently, there is still a great deal at stake where clients are concerned. Researchers (Hoadley \& Ensor, [ 21] ; Lareau, [ 31] ) are clear that distinctions exist between social class groups. When counselors do not acknowledge clients' social class, they may diminish clients' sense of self, identity, and culture; impose middle-class values; and have difficulty building and maintaining the counseling relationship (Vontress, [ 54] ). It is reasonable to conclude that when participants lack social class awareness and understanding in the interview context, their current degree of awareness and understanding is most likely present in their work with clients. As a result, it is possible that counselors may unintentionally impose middle-class values on their clients and inadvertently reject client worldviews that deviate from middle social class norms.

Because of the scant counseling research about social class and SES, many counselors have not had the opportunity to determine their social class position, values, beliefs, and biases, nor have they had the opportunity to develop their social class consciousness (Liu, [ 33] ). Understanding one's social class consciousness includes developing one's personal social class and SES awareness, so that it can extend to professional social class and SES awareness, knowledge, and skills. During their counselor training programs, many counselors have done this work in cultural areas such as race, gender, and sexual orientation, yet often social class does not receive the same attention. In terms of other cultural factors, the focus on social class is not meant to trump or negate other multicultural identities (Constantine, [11] ; Pearce, Down, \& Moore, [ 40] ). In fact, the intersections that often occur for people with multiple nondominant group identities increase the likelihood that these persons will experience heightened marginalization (Crenshaw, [ 14] ). From this perspective, it is even more critical for counselors in all work settings to endeavor to increase their social class awareness and understanding not only to better grasp clients' worldviews, experiences, and levels of oppression but also to be more effective therapeutically. The counseling profession would benefit from future studies that examine clients' intersectionality and how social class plays a role in their identities. Furthermore, it would be helpful to expand and sample intentionally demographic groups not represented by the sample in this study (e.g., men, additional racial/ethnic groups) to diversify the way social class and SES are understood in different cultural groups and to understand if the findings here are transferable to other demographic groups. In addition, because only LPCs who work in clinical mental health or private practice settings were included in this study, future research warrants understanding how counselors with other professional identities (e.g., school counselors, couple and family counselors) understand social class and SES.

Finally, these findings substantiate researchers' (e.g., Liu, Ali, et al., [ 34] ) call for counselors to gain further knowledge about social class and SES and how they function in clients' lives. The imprecise or incorrect use of the term social class is not a simple, semantic mistake. It is an issue in which meaning, value, and depth of client experiences can be masked, diminished, ignored, or simply reduced to an economic bottom line. Although it 
may be developmentally expected, counselors' lack of social class understanding and awareness may cause clients to suffer. By exploring the multiple layers of social class, counselors may enhance their empathy and relationship-building abilities, uncover client's unearthed strengths, and thereby empower clients toward increased health and well-being. To do this, counselors must develop their own social consciousness and increase their social class awareness, knowledge, and skills.

These findings indicate that it is important for counselors to gain further training so their understanding and knowledge about these terms become more comprehensive.

Therefore, this study raises many important questions to address in future research: How can counselors increase their social class consciousness, and what would motivate counselors to do so after such a long period of denying class as an aspect of culture? How, as a profession, can counselors initiate and sustain an open attitude about social class and encourage each other to broach issues related to social class with their clients? What skills are necessary to work competently with members of different social class groups?

\section{Conclusion}

For decades, television media images have flooded people in the United States with static, one-dimensional images of what social class groups are like and how people live. As pervasive as these images are, the United States continues to be a culture that denies the impact of social class on people's lives. Nine LPCs participated in semistructured interviews and described their awareness and understanding of social class and socioeconomic status. Participants described some aspects related to social class and SES when asked directly about these concepts, yet often they were unable to operationalize their descriptions of these terms when they discussed them during other points in the interview process. Findings suggest that participants' SES and social class awareness and understanding are limited because of developmental factors, which could lead to difficulties working with clients. Counselors may need to develop a stronger social class consciousness to provide clients with counseling services that affirm clients' social class worldviews rather than ignore or diminish their cultural experiences.

\section{References}

1 American Counseling Association. ( 2005 ). ACA code of ethics. Retrieved from http://www.counseling.org/Resources/aca-code-of-ethics.pdf

$\underline{2}$ American Psychological Association. ( 2010 ). Publication manual of the American Psychological Association ( 6th ed. ). Washington, DC : Author.

3 Anderson, W. T. ( 1990 ). Reality isn't what it used to be. New York, NY : HarperCollins.

4 Aronowitz, S. ( 2003 ). How class works. New Haven, CT : Yale University Press.

$\underline{5}$ Beeghley, L. ( 2000 ). The structure of social stratification in the United States (3rd ed. ). Needham Heights, MA : Allyn \& Bacon.

6 Bradbury, K., \& Katz, J. ( 2002 ). Are lifetime incomes growing more unequal? Looking at new evidence on family income mobility. Regional Review, 12 ( 4 ). Retrieved from http://www.bos.frb.org/economic/nerr/rr2002/q4/issues.pdf

7 Brown, M. T., Fukunaga, C., Umemoto, D., \& Wicker, L. ( 1996 ). Annual review, 1990-1996: Social class, work, and retirement behavior. Journal of Vocational Behavior, 49, 159 - 189. doi: 10.1006/jvbe.1996.0039

8 Buckley, M. R. ( 2010 ). Grounded theory methodology. In C. J. Sheperis, J. S. Young, \& M. H. Daniels (Eds.), Counseling research: Quantitative, qualitative, and mixed methods (pp. 115-134 ). Upper Saddle River, NJ : Pearson.

9 Carsey, M., \& Werner, T. (Producers). ( 1988 ). Roseanne [Television series]. Los Angeles, CA : Viacom.

10 Christensen, T. M., \& Brumfield, K. A. ( 2010 ). Phenomenological designs: The philosophy of phenomenological research. In C. J. Sheperis, J. S. Young, \& M. H. Daniels (Eds.), Counseling research: Quantitative, qualitative, and mixed methods (pp. 135-150). Upper Saddle River, NJ : Pearson. 
11 Constantine, M. G. ( 2002 ). The intersection of race, ethnicity, gender, and social class in counseling: Examining selves in cultural contexts. Journal of Multicultural Counseling and Development, 30, 210 215. doi: 10.1002/j.2161-1912.2002.tb00520.x

12 Corbin, J. M., \& Strauss, A. ( 1990 ). Grounded theory research: Procedures, canons, and evaluative criteria. Qualitative Sociology, 13, 3-21. doi: 10.1007/BF00988593

13 Corbin, J. M., \& Strauss, A. C. ( 1998 ). Basics of qualitative research ( 2nd ed. ). Thousand Oaks, CA : Sage.

14 Crenshaw, K. ( 1991 ). Mapping the margins: Intersectionality, identity politics, and violence against women of color. Stanford Law Review, 43, 1241 - 1299. doi: 10.2307/1229039

15 Creswell, J. ( 2007 ). Qualitative inquiry and research design ( 2 nd ed. ). Thousand Oaks, CA : Sage.

16 Dunlop, S. (Producer). ( 2006 ). The real housewives of Orange County [Television series]. Coto de Caza, CA : Bravo Cable.

17 Gergen, K. J. ( 2000 ). The saturated self: Dilemmas of identity in contemporary life. New York, NY : Basic Books.

18 Gillies, V. ( 2006 ). Parenting, class, and culture: Exploring the context of childrearing. Community Practitioner, 79, $114-117$.

19 Hays, D. G., \& Wood, C. ( 2011 ). Infusing qualitative traditions in counseling research designs. Journal of Counseling \& Development, 89, 288 - 295. doi: 10.1002/j.1556-6678.2011.tb00091.x

20 Helms, J. E. ( 1992 ). A race is a nice thing to have: A guide to being a White person or understanding the White persons in your life. Topeka, KS : Content Communications.

21 Hoadley, U., \& Ensor, P. ( 2009 ). Teachers' social class, professional dispositions and pedagogic practice. Teaching and Teacher Education, 25, 876 - 886. doi: 10.1016/j.tate.2009.01.014

22 Holton, J. A. ( 2007 ). The coding process and its challenges. In A. Bryant \& K. Charmez (Eds.), The Sage handbook of grounded theory (pp. $265-290$ ). Thousand Oaks, CA : Sage.

23 Hunt, B. ( 2011 ). Publishing qualitative research in counseling journals. Journal of Counseling \& Development, 89, 296 - 300. doi: 10.1002/j.1556-6678.2011.tb00092.x

24 Jones, Q. (Producer). ( 1990 ). The fresh prince of Bel-Air [Television series]. Hollywood, CA : National Broadcasting Company Productions.

$25 \mathrm{Kim}$, S., \& Cardemil, E. ( 2012 ). Effective psychotherapy with low-income clients: The importance of attending to social class. Journal of Contemporary Psychotherapy, 42, 27 - 35. doi: 10.1007/s10879-011-9194-0

$\underline{26}$ Knapp, T. R. ( 1998 ). Quantitative nursing research. Thousand Oaks, CA : Sage.

27 Kraus, M. W., Côté, S., \& Keltner, D. ( 2010 ). Social class, contextualism, and empathetic accuracy. Psychological Science, 21, 1716 - 1723. doi: 10.1177/0956797610387613

$\underline{28}$ Kraus, M. W., Piff, P. K., Mendoza-Denton, R., Rheinschmidt, M. L., \& Keltner, D. ( 2012 ). Social class, solipsism, and contextualism: How the rich are different from the poor. Psychological Review, 119, 546 572. doi: $10.1037 / a 0028756$

29 Kudrna, L., Furnham, A., \& Swami, V. ( 2010 ). The influence of social class salience on self-assessed intelligence. Social Behavior and Personality, 38, 859 - 864. doi: 10.2224/sbp.2010.38.6.861

30 Kurtz, R. A. ( 1966 ). The public use of sociological concepts: Culture and social class. The American Psychologist, 1, $187-189$.

31 Lareau, A. ( 2011 ). Unequal childhoods: Class, race and family life ( 2 nd ed. ). Berkeley : University of California Press.

32 Liu, W. M. ( 2001 ). Expanding our understanding of multiculturalism: Developing a social class worldview model. In D. B. Pope-Davis \& H. L. K. Coleman (Eds.), The intersection of race, class, and gender in counseling psychology (pp. 127-170). Thousand Oaks, CA : Sage.

33 Liu, W. M. ( 2011 ). Social class and the classism in the helping professions. Thousand Oaks, CA : Sage.

34 Liu, W. M., Ali, S. R., Soleck, G., Hopps, J., Dunston, K., \& Pickett, T., Jr. ( 2004 ). Using social class in counseling psychology research. Journal of Counseling Psychology, 51, $3-18$. doi: 10.1037/00220167.51.1.3 
$\underline{35}$ Liu, W. M., Soleck, G., Hopps, J., Dunston, K., \& Pickett, T., Jr. ( 2004 ). A new framework to understand social class in counseling: The Social Class Worldview Model and modern classism theory. Journal of Multicultural Counseling and Development, 32, 95 - 122. doi: 10.1002/j.2161-1912.2004.tb00364.x

36 Lorion, R. P. ( 1974 ). Patient and therapist variables in the treatment of low-income patients. Psychological Bulletin, 81, $344-354$. doi: 10.1037/h0036484

37 Muntaner, C., Eaton, W. W., \& Diala, C. C. ( 2000 ). Social inequalities in mental health: A review of concepts and underlying assumptions. Health, 4, 89 - 113. doi: 10.1177/136345930000400105

38 Ostrove, J. M., \& Cole, E. R. ( 2003 ). Privileging class: Toward a critical psychology of social class in the context of education. Journal of Social Issues, 59, 677 - 692. doi: 10.1046/j.0022-4537.2003.00084.x

39 Payne, R. K. ( 2005 ). A framework for understanding poverty ( 4th ed. ) Highlands, TX : aha! Process.

40 Pearce, J., Down, B., \& Moore, E. ( 2008 ). Social class, identity, and the "good" student: Negotiating university culture. Australian Journal of Education, 52, 257 - 271. doi: 10.1177/000494410805200304

41 Pettit, I. B., Pettit, T. F., \& Welkowitz, J. ( 1974 ). Relationship between values, social class, and duration of psychotherapy. Journal of Consulting and Clinical Psychology, 42, 482 - 490. doi: 10.1037/h0036716

42 Phinney, J. S. ( 1993 ). A three-stage model of ethnic identity development. In M. B. Spencer \& G. Knight (Eds.), Ethnic identity: Formation and transmission among Hispanics and other minorities (pp. 61 - 79 ). Albany : State University of New York Press.

43 Poster, M. (Producer), \& Gips, A. (Director). ( 2013 ). Welcome to myrtle manor [Television series]. New York, NY : Jupiter Entertainment.

44 Ranchor, A. V., Bouma, J., \& Sanderman, R. ( 1996 ). Vulnerability and social class: Differential patterns of personality and social support over the social classes. Personality and Individual Differences, 20, 229 237. doi: 10.1016/0191-8869(95)00156-5

45 Rossman, G. B., \& Rallis, S. F. ( 2012 ). Learning in the field: An introduction to qualitative research ( 3rd ed. ). Thousand Oaks, CA: Sage.

46 Sawhill, I. V., \& Morton, J. E. ( 2007 ). Economic mobility: Is the American dream alive and well? Retrieved from Brookings Institution website: http://www.brookings.edu/research/papers/2007/05/useconomicsmorton

47 Seidman, I. ( 2006 ). Interviewing as qualitative research ( $3 r d$ ed. ). New York, NY: Teachers College Press.

$\underline{48}$ Simon, L., \& Ransohoff, M. (Producers). ( 1962 ). The Beverly hillbillies [Television series]. New York, NY : CBS.

49 Sladen, B. J. ( 1982 ). Effects of race and socioeconomic status on the perception of process variables in counseling. Journal of Counseling Psychology, 29, 560 - 566. doi: 10.1037/0022-0167.29.6.560

50 Smith, L. ( 2006 ). Addressing classism, extending multicultural competence, and serving the poor. American Psychologist, 61, 338 - 339. doi: 10.1037/0003-066X.61.4.338

51 Smith, L., Li, V., Dykema, S., Hamlet, D., \& Shellman, A. ( 2013 ). "Honoring somebody that society doesn't honor:" Therapists working in the context of poverty. Journal of Clinical Psychology, 69, 138-151. doi: 10.1002/jclp.21953

52 Staton, A. R., Evans, W., \& Lucey, C. ( 2012 ). Understanding social class in the United States. In D. C. Sturm \& D. M. Gibson (Eds.), Social class and the helping professions (pp. 17-34). New York, NY : Routledge.

53 Sue, D. W., \& Sue, D. ( 1977 ). Barriers to effective cross-cultural counseling. Journal of Counseling Psychology, 24, 420 - 429. doi: 10.1037/0022-0167.24.5.420

$\underline{54}$ Vontress, C. E. ( 2011 ). Social class influences on counseling. Counseling and Human Development, 44, 1 12.

55 Warner, W. L., Meeker, M., \& Eells, K. ( 1960 ). Social class in America. New York, NY : Harper \& Row.

$\underline{56}$ West-Olatunji, C., \& Gibson, D. M. ( 2012 ). A global and historical introduction to social class. In D. C. Sturm \& D. M. Gibson (Eds.), Social class and the helping professions (pp. 17-34 ). New York, NY : Routledge. 